\title{
Las políticas monetarias y cambiarias del FMI, y su impacto sobre los derechos humanos
}

\author{
The IMF's monetary and exchange rate policies, \\ and their impact on human rights
}

\author{
Alfredo F. Calcagno ${ }^{1}$ \\ Universidad Nacional de Quilmes, Argentina
}

Revista Derechos en Acción ISSN 2525-1678/ e-ISSN 2525-1686

Año 6/No 18 Verano 2020-2021 (21 diciembre a 20 marzo), 517-555

DOI: https://doi.org/10.24215/25251678e490

Resumen: La misión original del FMI era organizar un Sistema Monetario y Financiero Internacional estable, que favoreciera el comercio internacional y corrigiera los desequilibrios con el menor costo posible. Con tal fin, se confirió al FMI poderes de supervisión sobre las políticas monetarias y cambiarias de los países miembros, y la potestad de incidir sobre ellas en ocasión de los programas de asistencia acordados con los países en dificultades. En la práctica, las políticas propugnadas por el FMI han agravado tanto la inestabilidad económica y financiera internacional como el costo económico y social de las crisis resultantes, lo cual ha vulnerado los derechos humanos económicos, sociales y culturales en los países afectados. Sus políticas macroeconómicas procíclicas han sido costosas desde el punto de vista social e inefectivas desde el económico, en tanto sus reformas estructurales han vulnerado la soberanía de los países. Los resultados de los programas, sistemáticamente alejados de los proyectados, evidencian deficiencias analíticas que han sido parcialmente reconocidas en la teoría, sin que el contenido de los programas del FMI variara substancialmente. Una reforma del FMI, que refleje la nueva relación de fuerzas en la economía mundial, es indispensable para que esa institución retome su misión original y contribuya a la

Profesor de la Universidad Nacional de Quilmes. Ex funcionario de CEPAL y UNCTAD. 
realización de los derechos humanos reconocidos por la Organización de las Naciones Unidas, de la cual forma parte.

Abstract: The IMF's original mission was to organize a stable International Monetary and Financial System that would favor international trade and correct imbalances at the lowest possible cost. To this end, the IMF was given supervisory powers over monetary and exchange rate policies of member countries, and the power to influence them in the context of assistance programs agreed with countries in difficulty. In practice, the policies advocated by the IMF have aggravated both international economic and financial instability as well as the economic and social cost of the resulting crises, violating economic, social and cultural human rights in the affected countries. Its pro-cyclical macroeconomic policies have been socially costly and economically ineffective, while its structural reforms have undermined the sovereignty of countries. The results of the programs, systematically far from those projected, show analytical deficiencies that have been partially recognized in theory, without the content of IMF programs changing substantially. A reform of the IMF, reflecting the new balance of power in the world economy, is essential if this institution is to resume its original mission and contribute to the realization of the human rights recognized by the United Nations, of which it is part.

\section{Introducción}

Con frecuencia se presentan los temas monetarios y cambiarios como cuestiones técnicas cuyo manejo se debe mantener alejado de consideraciones políticas. De acuerdo a la teoría neoclásica de las finanzas, habiendo competencia, los bancos son intermediarios pasivos y son los mecanismos impersonales de mercado los que asignan los recursos financieros. Dentro de esa perspectiva, las autoridades económicas no deben interferir en los mercados, mediante la fijación de tasas de interés, la manipulación del tipo de cambio, el direccionamiento del crédito o el financiamiento monetario del déficit fiscal. Para evitar la "politización" de los mercados monetario y cambiario, 
se busca establecer bancos centrales independientes del poder político que administren cuestiones técnicas sin rendir cuentas a la ciudadanía. En efecto, "la solución de los problemas técnicos escapa a la discusión pública". ${ }^{2}$

La intención de este artículo, por el contrario, es mostrar que las políticas monetarias y cambiarias son eminentemente eso: "políticas". Deben utilizar, como es natural, ciertos instrumentos técnicos de manera apropiada, pero ello no quita que los objetivos sean políticos. En efecto, la moneda (que en sus formas modernas proviene del crédito bancario) dista mucho de ser "neutra". Adherimos aquí a una tradición de la teoría monetaria inaugurada en el siglo XVIII por Richard Cantillon, que sostiene que las vías por las cuales se crea la moneda, sus destinatarios y el uso que se le da tienen efectos sobre el crecimiento económico, la estructura sectorial, los precios relativos, la distribución del ingreso y la configuración del poder económico. ${ }^{3}$ Por ende, a través de sus decisiones, las autoridades monetarias inciden de manera decisiva (para bien o para mal) en el desarrollo de un país y, de ese modo, en la realización de los derechos humanos, sobre todo económicos y sociales. No se trata solamente del efecto de sus políticas sobre el crecimiento: se trata de cómo modelan un tipo de desarrollo, inclusivo o excluyente, autónomo o subordinado. En suma, al no ser neutras, las políticas monetarias y cambiarias pueden contribuir a un desarrollo económico respetuoso de los derechos humanos, o bien obstaculizarlo.

Esta tensión entre la concepción tecnocrática de las cuestiones monetarias y cambiarias y la concepción política de las mismas, se agudiza cuando interviene un actor exterior a las instituciones nacionales: el Fondo Monetario Internacional. Si se tratara de una cuestión meramente técnica, la asistencia de los profesionales del FMI podría ser una ayuda para la gestión local;

\footnotetext{
2 Jürgen Habermas, La technique et la science comme idéologie, (Gallimard, 1973), 42.

3 Véase Alfredo Eric Calcagno, Alfredo F. Calcagno y Eric Calcagno, Manual del Estado, (Catálogos, Buenos Aires, 2018), Libro II, capítulo 7.
} 
pero, tratándose de decisiones políticas, surgen preocupaciones legítimas sobre la intromisión de intereses foráneos en cuestiones que hacen a la soberanía nacional y que tienen una incidencia directa sobre los derechos humanos de la población.

En la sección que sigue presentamos el mandato histórico que recibió el FMI cuando fue creado en 1944, en particular en lo que se refiere a las políticas monetarias y los regímenes cambiarios de los países miembros. En la tercera sección examinamos el contenido de las políticas monetarias y cambiarias que el FMI ha impulsado en los países que solicitan su asistencia crediticia; algunas de esas condiciones se refieren a las políticas macroeconómicas coyunturales, en tanto otras tratan de reformas estructurales. Analizamos a continuación los resultados de esas políticas monetarias y cambiarias; mostramos que estos difieren de manera sistemática de los proyectados, y que conllevan un costo económico, social y político elevado. En una quinta sección exponemos las críticas que ha recibido el FMI y discutimos las respuestas que les ha dado. Estimamos que tales respuestas son insuficientes para que el FMI retome su mandato original y, sobre todo, para que respete en su acción los derechos humanos que, como argumentamos en este artículo, ha violado de manera reiterada. En una breve conclusión recapitulamos las ideas fuerza de este trabajo.

\section{Creación y mandato original del FMI}

Aun antes de concluir la Segunda Guerra Mundial, las potencias aliadas se ocuparon de diseñar el orden económico de posguerra. Había que reconstruir los países beligerantes, favorecer la recuperación del comercio internacional y evitar los desórdenes monetarios del período de entreguerras. Con tales fines, la Conferencia de Bretton Woods (julio de 1944) fundó el Banco Internacional de Reconstrucción y Fomento (el "Banco Mundial"), encargado de financiar la reconstrucción y el desarrollo, y el Fondo Monetario Internacional, piedra angular del nuevo sistema monetario y financiero internacional (SMFI). 
Con el nuevo SMFI, los vencedores de la guerra buscaban no repetir la experiencia que siguió a la Primera Guerra Mundial. En ese entonces, el costoso intento de restablecer el patrón oro y su colapso con la crisis de 1930 hizo que cada país se sintiera libre de adoptar el régimen cambiario que quisiera, y tratara de sacar ventaja con devaluaciones competitivas. Al mismo tiempo, se generalizó el proteccionismo y se multiplicaron los acuerdos comerciales y de pagos bilaterales, que fragmentaron el comercio mundial. Así, si un país quería mantener o incrementar sus exportaciones a otro, tenía también que aumentar sus importaciones de este último, aunque ni esas importaciones ni ese proveedor hubieran sido los preferidos en un marco de comercio internacional más libre. ${ }^{4}$

Con tales precedentes, los arquitectos del FMI buscaron instaurar un sistema multilateral de pagos para las transacciones corrientes que facilitaría la expansión del comercio internacional y, por esa vía, contribuiría al logro de altos niveles de empleo y de ingreso real. ${ }^{5}$ Para ello, el SMFI eliminaba las restricciones a las transacciones en el mercado cambiario y promovía un sistema de tipos de cambio estables, monitoreados por el propio FMI, del que las devaluaciones competitivas quedaban explícitamente excluidas. Los países miembros también se comprometían a no participar en regímenes monetarios discriminatorios ni en prácticas de tipos de cambio múltiples. ${ }^{6}$ Notemos que los miembros del FMI conservaban su potestad para controlar los movimientos de capitales, siempre y cuando ello no significara una restricción a los pagos de las transacciones corrientes. ${ }^{7}$

4 El más famoso de esos acuerdos firmados por la Argentina es el Pacto Roca-Runciman, de 1933, pero el país tenía también convenios bilaterales de pagos con Alemania, Holanda, Bélgica, Suiza, España y Brasil.

5 Véase el Artículo I del Convenio Constitutivo del FMI, que establece los propósitos de la institución.

6 FMI, Convenio Constitutivo, Art. VIII, sección 3.

7 Ibid., Artículo VI, sección 3. 
Por otra parte, el nuevo SMFI tenía que adoptar algún procedimiento para evitar (o corregir) desequilibrios prolongados en las balanzas de pagos, que de otro modo llevarían a la acumulación de acreencias incobrables para algunos países miembros y de deudas impagables para otros. De producirse tales desequilibrios, el FMI ofrecería financiamiento al país deficitario, pero al mismo tiempo lo induciría a disminuir su saldo negativo. El financiamiento debía darles la oportunidad a los países deficitarios "de que corrijan los desequilibrios de sus balanzas de pagos sin recurrir a medidas perniciosas para la prosperidad nacional o internacional", 8 esto es, evitando o limitando la contracción de su economía. Sin embargo, se fijarían "garantías adecuadas" a esos préstamos para asegurar su repago: concretamente, los créditos vendrían atados a condiciones de política económica, con el fin de inducir un ajuste de la balanza de pagos. De este modo, el FMI podía pedirle al país en cuestión que devaluara su moneda y contrajera su gasto interno. Esas medidas reducirían las importaciones y alentarían las exportaciones, corregirían así el desequilibrio externo y harían posible el repago del préstamo concedido.

Cabe hacer aquí dos observaciones. Por una parte, vemos que al país que atraviesa dificultades en su balanza de pagos y ya se encuentra, muchas veces, en recesión económica, el FMI le fija condiciones que agravan esa recesión. Hay una contradicción entre el objetivo oficial del FMI, que, como vimos, es evitar "medidas perniciosas para la prosperidad nacional e internacional", y las condiciones mencionadas que profundizan la recesión en lugar de atenuarla. Por otra parte, observamos que todo el peso del ajuste recae sobre los países deficitarios, librando a los excedentarios de toda responsabilidad. Hubiera sido posible instaurar un mecanismo simétrico de ajuste, en el cual los países excedentarios estarían obligados a incrementar su gasto y sus importaciones; de ese modo sería posible atenuar

8 Ibid., Artículo I. 
el ajuste recesivo en los países deficitarios, y se compensaría su impacto negativo sobre la economía mundial.

De hecho, ese ajuste simétrico era una de las propuestas más interesantes del negociador británico, John Maynard Keynes, durante el debate previo a la constitución del FMI. Keynes también proponía que el FMI funcionara como una caja de compensación para el comercio internacional y como un banco central mundial, que emitiría una moneda internacional (que propuso llamar "grammor" o "bancor") en función de las necesidades de la economía global. Nada de esto fue aceptado por los Estados Unidos, que quisieron colocar al dólar como la moneda internacional (convertible al oro a una tasa fija, hasta 1971) y controlar directamente la oferta de liquidez global. También rechazaban, por cierto, permitir que el FMI los obligara a aplicar políticas expansivas para reequilibrar los intercambios internacionales. Así, por más que el proyecto de Keynes fuera superior desde el punto de vista intelectual y que se adaptara mejor a las necesidades de la economía mundial, prevaleció el defendido por el negociador norteamericano, Harry Dexter White, que se apoyaba en el poderío económico, político y militar de la potencia dominante de ese momento. Ese dominio se

9 Véase John M. Keynes(1941), "Proposals for an International CurrencyUnion”, 18 de noviembre de 1941, disponible en: http://la.utexas.edu/users/hcleaver/368/368keynesoncutable.pdf. Allí planteaba que había que "poner por lo menos tanta presión para que ajuste el país acreedor que para que ajuste el deudor", ya que si se permite que el acreedor permanezca pasivo (es decir, que no aprecie su moneda ni que aumente su gasto y sus importaciones), "se deja al país deudor frente a una tarea imposible". Esta idea fue retomada durante la crisis de la zona euro en 2010-2013: entonces se alzaron voces para que los países excedentarios (Alemania y los Países Bajos) incrementaran sus gastos, y aliviaran así la recesión de los países deficitarios (Portugal, Italia, Irlanda, Grecia, España, maliciosamente llamados los PIIGS, por sus iniciales en inglés); véase Michel Aglietta, Zone euro, éclatement ou fédération, (Michalon, París, 2012). La necesidad de aplicar políticas fiscales, monetarias y de ingresos expansivas de manera coordinada (sobre todo por parte de los países excedentarios) fue reiterada por la UNCTAD en varias ediciones de su informe anual Trade and Development Report, a partir de 2010. Un argumento similar se encuentra en Jorge Carrera, “El G20 frente a los desequilibrios externos y la distribución regresiva del ingreso", 33 Análisis, Friedrich Ebert Siftung Argentina, noviembre de 2018. 
reflejó también en la distribución de cuotas y de poder de voto dentro del FMI, en la cual los Estados Unidos tuvieron siempre un peso preponderante. ${ }^{10}$

En suma, la constitución del FMI reflejó dos realidades: la voluntad compartida de organizar un sistema monetario y financiero que evitara un desorden económico como el que siguió a la primera guerra mundial y que favoreciera la expansión del comercio internacional, y el predominio de los Estados Unidos en el diseño del nuevo orden internacional.

\section{Las políticas cambiarias y monetarias en los programas del FMI: ajuste coyuntural y reforma estructural}

Vemos que, desde su concepción, el FMI ejerció una supervisión sobre las políticas cambiarias de los países. En un principio, los países miembros debían adherir a un sistema de tipos de cambio fijos, modificables en caso de necesidad, pero solamente con la aprobación del FMI; era ésta una limitación significativa para la autonomía de los países, sobre todo de los subdesarrollados, que entregaban a una institución controlada por países desarrollados la potestad de fijar su política cambiaria. Este sistema funcionó hasta 1971, cuando los Estados Unidos decidieron de manera unilateral cancelar la convertibilidad del dólar en oro y devaluar su moneda, todo ello sin la menor consulta (ni hablemos de autorización) con el FMI. Pero aun después de abandonarse el sistema de tipo de cambio fijo y de enmendarse sus estatutos para admitir una pluralidad de regímenes cambiarios posibles (incluyendo la flotación), el FMI mantuvo un poder de supervisión y control sobre las políticas cambiarias.

En efecto, el Convenio Constitutivo del FMI establece que los países miembros "se comprometen a colaborar con el Fondo y entre sí para establecer regímenes de cambios ordenados y

\footnotetext{
10 Al momento de la creación del FMI, con 45 países miembros, los EE. UU. reunían 31 \% de las cuotas. Al día de hoy, con 190 países miembros, los EE.UU. suman 17,4 \% de las cuotas. La distribución de los votos dentro del FMI, recordémoslo, es casi idéntica a la de las cuotas.
} 
promover un sistema estable de tipos de cambio", y a evitar toda manipulación del tipo de cambio destinada a "impedir el ajuste de la balanza de pagos u obtener ventajas competitivas desleales frente a otros países miembros". Para controlar esos compromisos, "el Fondo ejercerá una firme supervisión de las políticas de tipos de cambio de los países miembros y adoptará principios específicos que sirvan de orientación a todos ellos con respecto a esas políticas. Los países miembros proporcionarán al Fondo la información necesaria para ejercer esa supervisión y, a solicitud del Fondo, le consultarán sobre sus políticas de tipos de cambio". ${ }^{11}$

La acción del FMI sobre las políticas cambiaria y monetaria se ha ejercido en dos planos. Uno es el del ajuste coyuntural: opera cuando un país requiere asistencia para enfrentar un desequilibrio en su balanza de pagos y el Fondo la condiciona a la aplicación de determinadas políticas macroeconómicas. El segundo se refiere al ordenamiento institucional, y se ejerce cuando el FMI incide en la adopción de determinados sistemas cambiarios o de ciertos principios de política monetaria.

El ajuste coyuntural es una condición típica de los Acuerdos Stand By (ASB), que fue el único tipo de programa crediticio del FMI hasta 1974. En los ASB, el FMI facilita un crédito de corto plazo para enfrentar un déficit externo, sujeto a condiciones de política destinadas a eliminar ese déficit y garantizar el reembolso del crédito. Las condiciones básicas consisten en políticas fiscales y monetarias restrictivas, destinadas a reducir la demanda agregada; en general, las completa una devaluación de la moneda, destinada a limitar importaciones y alentar exportaciones. El marco conceptual que justifica esas políticas se conoce como el "enfoque de absorción", según el cual el déficit en cuenta corriente se debe a un nivel de "absorción" (es decir, al nivel de consumo e inversión internos) superior a

11 FMI, Convenio constitutivo, Artículo IV. Estas disposiciones dieron origen a las "Consultas del Artículo IV" que el staff del Fondo conduce con cada país, y a las inspecciones e informes correspondientes. 
la producción local. ${ }^{12}$ Dentro de ese marco analítico del FMI, tuvo importancia el llamado "enfoque monetario de la balanza de pagos", que se sitúa en la tradición de la teoría cuantitativa de la moneda; afirma éste que la excesiva creación monetaria es la que alimenta un gasto excesivo, que a su vez genera un desequilibrio externo. ${ }^{13}$

Además de corregir los excesos en el gasto, las políticas fiscal y monetaria restrictivas apuntan a sortear las presiones financieras típicas de situaciones de crisis: el aumento de las tasas de interés busca limitar las salidas de capital y poner coto a la desvalorización de la moneda, en tanto el ajuste fiscal debe lanzar una señal de austeridad a los mercados, y de ese modo recuperar su confianza.

A mediados de los años setenta, el FMI introdujo el Servicio Ampliado del Fondo (SAF) para enfrentar problemas externos de mediano y largo plazo. Se trata de programas de más largo plazo que los ASB, que a las condiciones macroeconómicas habituales agregan una serie de reformas de largo plazo, con las que buscan corregir determinados problemas institucionales o de la estructura económica. En esta línea, desde mediados de los ochenta, se sucedieron nuevos tipos de programas, centrados en la aplicación de reformas estructurales, como respuesta a la "crisis de la deuda" que afectó con fuerza a los países latinoamericanos. ${ }^{14}$ En realidad, las condiciones estructurales se volvieron habituales incluso en los Acuerdos Stand By.

El FMI asumió así un papel preponderante (junto al Banco Mundial) en la ejecución de la "Estrategia de la deuda" enunciada por el Secretario del Tesoro de los Estados Unidos James

\footnotetext{
12 Véase Michael Mussa y Miguel Savastano, "The IMF approach to economic stabilization". Working Paper 99/104, Fondo Monetario Internacional, (Washington D.C., 1999).

13 Michel Aglietta y Sandra Moatti. Le FMI, de l'ordre monétaire aux désordres financiers, (Economica, París, 2000).

14 En 1986 se crea el Servicio de Ajuste Estructural, reemplazado luego por el Servicio Reforzado de Ajuste Estructural y el Servicio para el Crecimiento y la Lucha contra la Pobreza.
} 
Baker III. ${ }^{15}$ Esa estrategia buscaba no solamente zanjar los problemas de pago de los países en desarrollo sobreendeudados, sino conducirlos por un camino de reformas neoliberales, que John Williamson llamaría luego el "Consenso de Washington". ${ }^{16}$

Estas reformas estaban orientadas a "reducir las distorsiones impuestas por el gobierno y otras rigideces estructurales e institucionales que afectan la eficiente asignación de recursos en la economía y obstaculizan el crecimiento". Abarcaban los más diversos aspectos de la economía, como "la liberalización comercial, la liberalización de los precios, la reforma del mercado cambiario, la reforma fiscal, la reforma del gasto público, la reforma previsional, la reforma del sector financiero, la reestructuración del sistema bancario, la reforma del mercado laboral, y el fortalecimiento de las redes de seguridad social". ${ }^{17}$

En el terreno monetario, el FMI impulsó la independencia de los Bancos Centrales, que ya no tendrían que seguir las instrucciones del Ministerio de Economía o de Hacienda para cubrir el déficit fiscal o para financiar un programa de desarrollo. Su meta principal, y muchas veces excluyente, debía ser el control de la inflación. La forma en que se alcanzaría esa meta dependía del régimen cambiario que se eligiera.

$\mathrm{Al}$ respecto, el FMI promovió, en las economías emergentes integradas a los mercados de capital, la adopción de regímenes cambiarios "extremos". Se trata de sistemas que establecían un tipo de cambio totalmente flexible (free floating), o totalmente rígido (hard peg), como era el régimen de convertibilidad

\footnotetext{
15 James A. Baker III (1975), "Statement by the Governor of the Fund and the Bank for the United States, James A. Baker III" en IMF, Summary Proceedings, 1985, disponible en: https://www.elibrary.imf.org/view/IMF015/24081-9781475580686/24081-9781475580686/ ch04.xml.

16 John Williamson, "What Washington Means by Policy Reform", en J. Williamson (ed.), Latin American adjustment: how much has happened?, Institute of International Economics, (Washington D.C., 1990).
}

17 Mussa y Savastano, op. cit., 22. 
argentino. ${ }^{18}$ En el primer caso, el Banco Central es dueño de la política monetaria: busca controlar la masa monetaria (mediante la regulación cuantitativa de la base monetaria y de los encajes bancarios) y/o fijar las tasas de interés para, por esa vía, regular la demanda agregada y la inflación. El marco preferido, en este esquema, es el de las "metas de inflación" (inflation targeting). El Banco Central puede utilizar la política monetaria o incluso alguna intervención en el mercado cambiario para suavizar los movimientos del tipo de cambio (la flotación cambiaria no sería entonces totalmente libre), pero no para defender un determinado tipo de cambio, cuya fijación queda en manos de las fuerzas de mercado.

En el caso de los tipos de cambio "super fijos", como era el de la Convertibilidad en la Argentina (vigente por ley 23928 desde abril de 1991, y formalmente abandonada en enero de 2002), el Banco Central defiende un tipo de cambio, que es el que permite controlar la inflación. En efecto, en una economía abierta al comercio internacional, los precios internos tienden a fijarse en función de los externos, y si el tipo de cambio no varía, la inflación local convergerá con la internacional. En este esquema, el Banco Central pierde en gran medida la capacidad de regular la oferta de moneda, ya que no hace más que emitir pesos cada vez que acumula reservas internacionales, y absorberlos cada vez que pierde reservas. En efecto, los sistemas rígidos de cambio super fijo (hard peg) le prohíben (o restringen a un mínimo) al Banco Central financiar al Tesoro público y otorgar redescuentos al sistema financiero, limitando su rol monetario a poco más que una caja de conversión.

La justificación conceptual para impulsar estos regímenes cambiarios extremos residía en la creencia que, en un marco de libre movimiento internacional de capitales, tales extremos

\footnotetext{
18 Véase Michael Mussa, Paul Masson, Alexander Swoboda, Esteban Jadresic, Paolo Mauro y Andrew Berg, "Exchange Rate Regimes in an Increasingly Integrated World Economy", IMF Occasional Paper 193, 2000, y Stanley Fischer, "Exchange rate regimes: is the bipolar view correct?", Journal of Economic Perspectives, XV, 2001, 3-24.
} 
eran más robustos que un sistema intermedio, en el cual la especulación financiera podía vaciar las reservas del Banco Central y forzar una mega-devaluación. En efecto, en la libre flotación, el Banco Central no compromete sus reservas: deja que el mercado encuentre el tipo de cambio "de equilibrio". En cuanto a los tipos de cambio "super fijos", se suponía que ninguna presión de mercado podría forzar una devaluación, en la medida en que toda la base monetaria estuviera respaldada por reservas internacionales, lo cual estaba garantizado por la regla antes explicada: el Banco Central solamente emitía contra la entrada de reservas internacionales. Puesto que se pensaba que el sistema era inexpugnable, se supuso que los agentes financieros no lo atacarían.

Lo que el FMI buscaba con esas recomendaciones era encontrar sistemas cambiarios y monetarios consistentes con la libre movilidad de capitales, que se convirtió en un objetivo en sí mismo. Los movimientos libres del capital, afirmaban los responsables del FMI, permiten una asignación más eficiente de los ahorros a nivel global y canalizan los recursos allí en donde tienen sus usos más productivos, lo cual aumenta el crecimiento económico y el bienestar; tales beneficios superarían con creces los costos que tal liberalización podría acarrear. De todos modos, agregaban, se trata de un paso inevitable dentro del camino del desarrollo, y es por ello que conviene que sea guiado por el FMI, del mismo modo que, anteriormente, este impulsó la liberalización comercial y la convertibilidad de los pagos en cuenta corriente. ${ }^{19}$

Es así como, en la Conferencia Anual de Hong Kong de septiembre de 1997, el Comité Interino de la Junta de Gobernadores del Fondo ${ }^{20}$ propuso una enmienda del Convenio Constitutivo

\footnotetext{
19 Véase Stanley Fischer, "Capital account liberalization and the role of the IMF", IMF Seminar, (septiembre de 1997). Disponible en https://www.imf.org/en/News/Articles/2015/09/28/ 04/53/sp091997.

20 Se trata de un comité de alto nivel, instituido en los años 1970 con el fin de asesorar a la Junta de Gobernadores del FMI en asuntos estratégicos.
} 
del FMI, "que haría de la liberalización de los movimientos de capital uno de los fines del Fondo y ampliaría, en la medida necesaria, su correspondiente jurisdicción estableciendo obligaciones claramente definidas y aplicadas en forma sistemática". ${ }^{21}$ Concretamente, se pensaba sustituir la potestad reconocida de manera explícita en el Artículo VI del Convenio Constitutivo, por la cual los países pueden aplicar controles para regular los movimientos internacionales de capital, por la prohibición de tales controles. Esta propuesta tuvo lugar pocas semanas después de iniciada la "crisis asiática", potente shock financiero que estaba vinculado, precisamente, con los movimientos de capital no supervisados. Esto hizo que la Junta de Gobernadores difiriera por un tiempo indeterminado esta decisión, que de haberse adoptado hubiera significado un condicionamiento muy fuerte para el manejo monetario y cambiario de los países miembros.

Al relajarse la presión por hacer obligatoria la liberalización de los flujos de capitales, también se debilitó la prédica por instaurar los regímenes cambiarios y monetarios que mejor se adecuaban, en teoría, a la apertura financiera. Sin embargo, fueron los malos resultados que mostraron los regímenes "extremos" los que, en años recientes, llevaron al FMI a aceptar de mejor grado la aplicación de sistemas cambiarios intermedios.

\section{Los resultados obtenidos}

\section{a. Inadecuación de los regímenes cambiarios extremos}

Los regímenes cambiarios y monetarios propuestos por el FMI durante los años noventa, como parte de las reformas liberales que caracterizaron esa década, no dieron los resultados anunciados. Se comprobó que no era posible, al menos para los países subdesarrollados abiertos a los flujos de capitales,

\footnotetext{
21 Fondo Monetario Internacional, Annual Report of the Executive Board for the Financial Year Ended April 30, (Washington D.C. 1998), 75.
} 
dejar flotar libremente su moneda sin que ello generara una inestabilidad macroeconómica imposible de sobrellevar. Dentro de un mundo en donde los movimientos de capital son a la vez muy cuantiosos y muy inestables, los Bancos Centrales se ven forzados a intervenir en el mercado cambiario, no solamente para atenuar los movimientos del tipo de cambio, sino también para evitar que los tipos de cambio real se aparten demasiado y por demasiado tiempo de niveles sustentables en el largo plazo. En efecto, aunque los gobiernos puedan suavizar las fluctuaciones cambiarias de corto plazo (lo que no es siempre posible), la flotación de las monedas conduce a períodos de apreciación real de las monedas locales, seguidos de shocks devaluatorios y crisis económicas. No es extraño, entonces, que incluso los países que registraban sus sistemas cambiarios en el FMI como sistemas de flotación, en realidad no dejaban flotar a sus monedas, e intervenían en sus mercados cambiarios con similar intensidad que quienes tenían regímenes "intermedios". ${ }^{22}$

Tampoco se verificó que los regímenes "super fijos", como la Convertibilidad argentina, fueran capaces de resistir la inestabilidad de los flujos de capitales. Ya con el shock de la "crisis del Tequila" se había podido comprobar que tal sistema monetario y cambiario acentuaba el funcionamiento pro-cíclico de la economía y no garantizaba la conversión de los depósitos bancarios en dólares, y que las reservas internacionales podían agotarse en el plazo de unos pocos meses. ${ }^{23}$ En la medida en que había congelado el tipo de cambio nominal en un nivel que terminó siendo poco competitivo (ya que, con la inflación inercial, el peso se había apreciado en términos reales), la Convertibilidad mostraba una contradicción intrínseca: si el país crecía, caía en un déficit en cuenta corriente que vaciaría las reservas; pero si no crecía, incurría en un déficit fiscal

\footnotetext{
22 Véase Guillermo A. Calvo y Carmen M. Reinhart. "Fear of floating", 2 The Quarterly Journal of Economics, Vol. 117, mayo de 2002, 379-408.

23 Alfredo Calcagno, "El régimen de convertibilidad y el sistema bancario en la Argentina", 61 Revista de la CEPAL, Santiago de Chile, abril de 1997.
} 
(por la menor recaudación) que no podía ser financiado por el Banco Central. La única forma de eludir esa contradicción era mediante una entrada ininterrumpida de capitales externos y un endeudamiento creciente, lo que en algún momento tenía que tocar un límite. Ese momento llegó con las crisis financieras de finales de los noventa (crisis asiática, brasileña y rusa), y la posterior fuga de capitales que sufrió la Argentina.

El problema, pudo comprobarse, era un sistema financiero internacional caracterizado por la masividad y la inestabilidad de los flujos de capitales, cuyas grandes oleadas de flujos y reflujos dependían principalmente de las autoridades monetarias de los países desarrollados, pero cuyos impactos más fuertes se verificaban en los países en desarrollo o "en transición", sobre todo los de ingreso medio. ${ }^{24}$ En tales países, en los cuales los sistemas financieros eran incapaces de absorber esos flujos de capitales, estos generaban una fuerte inestabilidad macroeconómica, sin que la política monetaria fuera capaz de contener los movimientos ni de mitigar sus efectos macroeconómicos, cualquiera fuera el sistema cambiario adoptado. ${ }^{25}$

Es así como el ciclo financiero global genera en múltiples países y de manera sincronizada episodios de auge y crisis (boom and bust). Y cuando sobrevienen las crisis, entra en escena el FMI y las políticas que impone a los países a través de la condicionalidad de sus préstamos.

\section{b. Los efectos de las políticas de ajuste}

El mecanismo de crédito más utilizado en tales casos es el Acuerdo Stand By (ASB). En este tipo de acuerdo, el país que

\footnotetext{
24 Véase Hélène Rey, “Dilemma not Trilemma: The Global Financial Cycle and Monetary Policy Independence", NBER, Working Paper 21162, (mayo de 2015), revisado en febrero de 2018.

25 Véase Andrew Haldane, "The big fish small pond problem". Discurso pronunciado en el Institute for New Economic Thinking Annual Conference, Bretton Woods, New Hampshire, el 9 de abril de 2011, disponible en: https://www.bis.org/review/r110413a.pdf, y UNCTAD, Trade and Development Report 2013, Adjusting to the changing dynamics of the world economy, (Nueva York y Ginebra, 2013).
} 
solicita la asistencia del FMI presenta una Carta de Intención, negociada previamente con el staff del Fondo, en donde se expone el programa económico al que se compromete el país. Los compromisos más importantes en una Carta de Intención son los "criterios de desempeño cuantitativos", valores de ciertas variables macroeconómicas que (se supone) el gobierno controla, como la emisión de base monetaria, el resultado fiscal primario y la acumulación de reservas internacionales. Otros compromisos son las "acciones preliminares" que el país debe adoptar aun antes de obtener la aprobación del crédito, y las "metas estructurales" como, por ejemplo, la reforma de la Carta Orgánica del Banco Central a la que se comprometió el gobierno argentino en 2018. Sin embargo, son sobre todo los criterios de desempeño cuantitativos los que revisan las misiones del FMI para aprobar los desembolsos trimestrales; si no se verifican, el Directorio del FMI suspende la asistencia, a menos que estime que el gobierno logrará corregir los desvíos, en cuyo caso otorga una "dispensa" (waiver).

Ya evocamos en el punto anterior el contenido estándar de las políticas "apoyadas por el FMI", ${ }^{26}$ que apuntan a reducir o revertir los déficits fiscal y comercial mediante políticas restrictivas y, con frecuencia, devaluaciones de la moneda. Si las metas de los programas son alcanzadas, se supone que el país recuperará el crecimiento y su capacidad de pago en el corto o mediano plazo. Los programas contienen entonces proyecciones macroeconómicas que deben ser consistentes con las metas cuantitativas y con la visión general de una recuperación económica que se alcanzaría gracias al financiamiento del FMI y a las medidas adoptadas.

Los gráficos 1, 2 y 3 consideran los ASB firmados luego de la crisis de fines de los noventa (asiática, rusa, etc.); los que siguieron a la crisis financiera de 2008; y los más recientes,

26 Tal es la fórmula para referirse al contenido de la condicionalidad, porque se parte del supuesto que los paquetes de ajuste "pertenecen" a los países, es decir que son los gobiernos los que los diseñan y adoptan, y que, si los considera apropiados, el FMI "apoya". 
cuando se trataban de programas nuevos, y no de la renovación de un ASB anterior o del reemplazo de un $\mathrm{SAF}^{27}$ En efecto, nuestra idea es evaluar el resultado de corto plazo de las políticas impulsadas por el FMI, que en tales casos los países ya venían aplicando hacía varios años. Para evaluar los programas, comparamos los valores que verificaron algunas variables macroeconómicas clave durante el año que siguió la adopción de los ASB, con las predicciones para ese mismo año contenidas en los acuerdos firmados. Las variables consideradas son la tasa de crecimiento del PBI, el saldo fiscal del Gobierno General y la cuenta corriente de la balanza de pagos, estos últimos expresados como porcentaje del PBI.

Gráfico 1. Previsiones y resultados para variables macroeconómicas clave en Acuerdos Stand By firmados entre 1997 y 2000, países escogidos

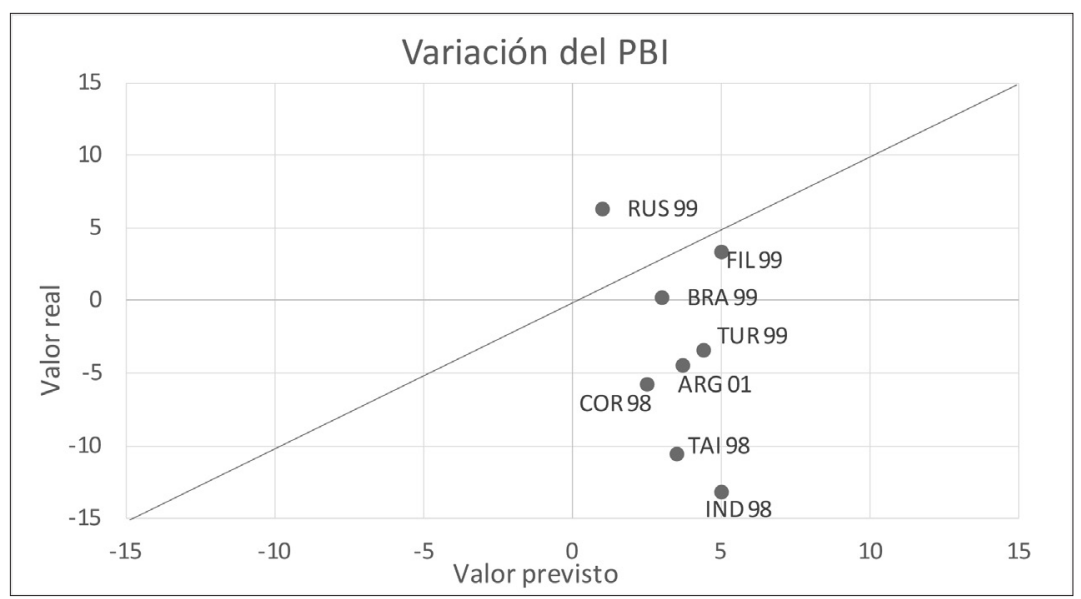

27 Los gráficos 1 y 2 son tomados de UNCTAD Trade and Development Report 2011, Postcrisis policy challenges in the world economy, (Nueva York y Ginebra, 2011). 

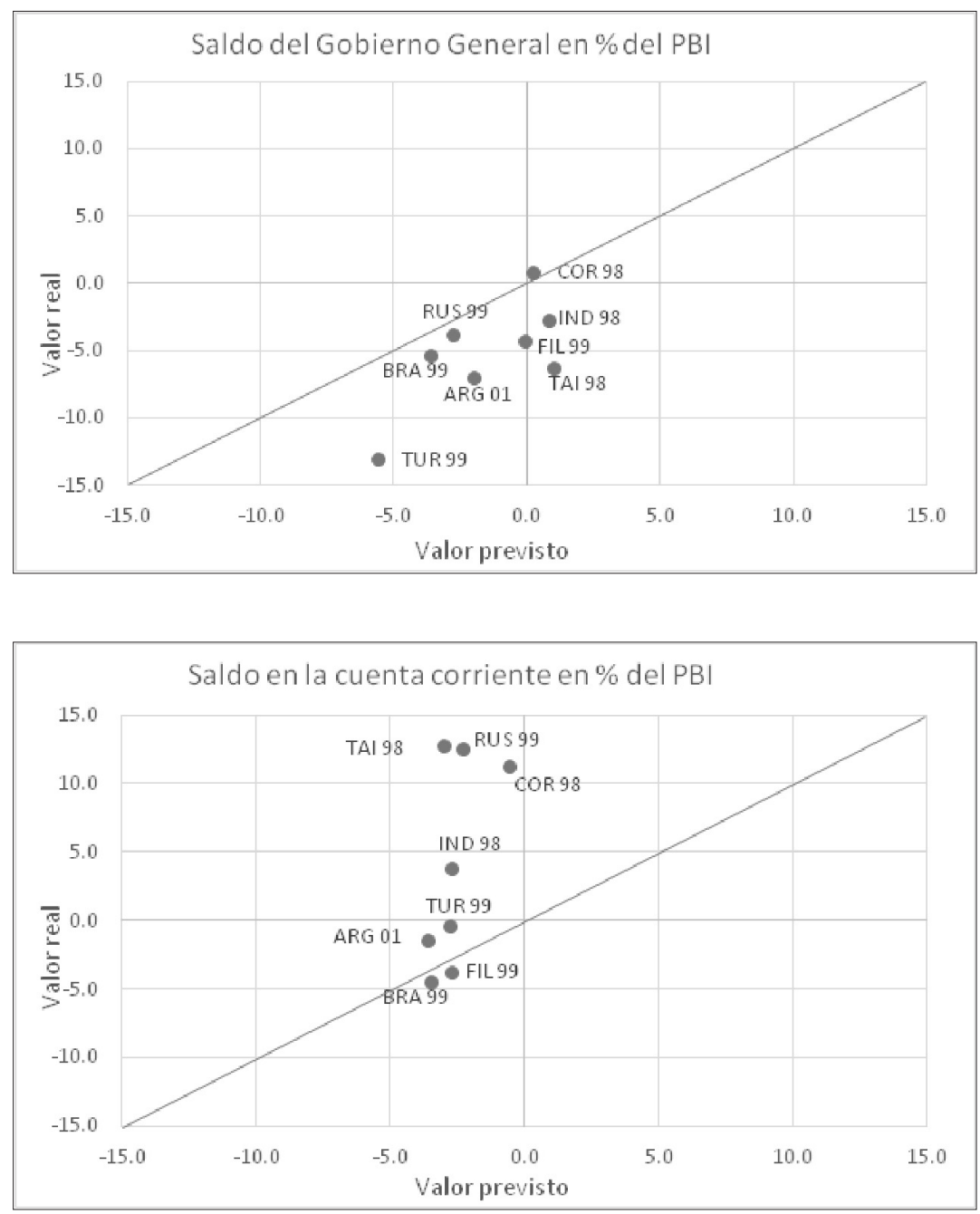

Fuente: FMI. Los países considerados son Argentina, Brasil, Rep. de Corea, Filipinas, Indonesia, Rusia, Tailandia y Turquía. Los años son los que siguen a la firma del ASB. 
Gráfico 2. Previsiones y resultados para variables macroeconómicas clave en Acuerdos Stand By, firmados entre 2008 y 2009, países escogidos
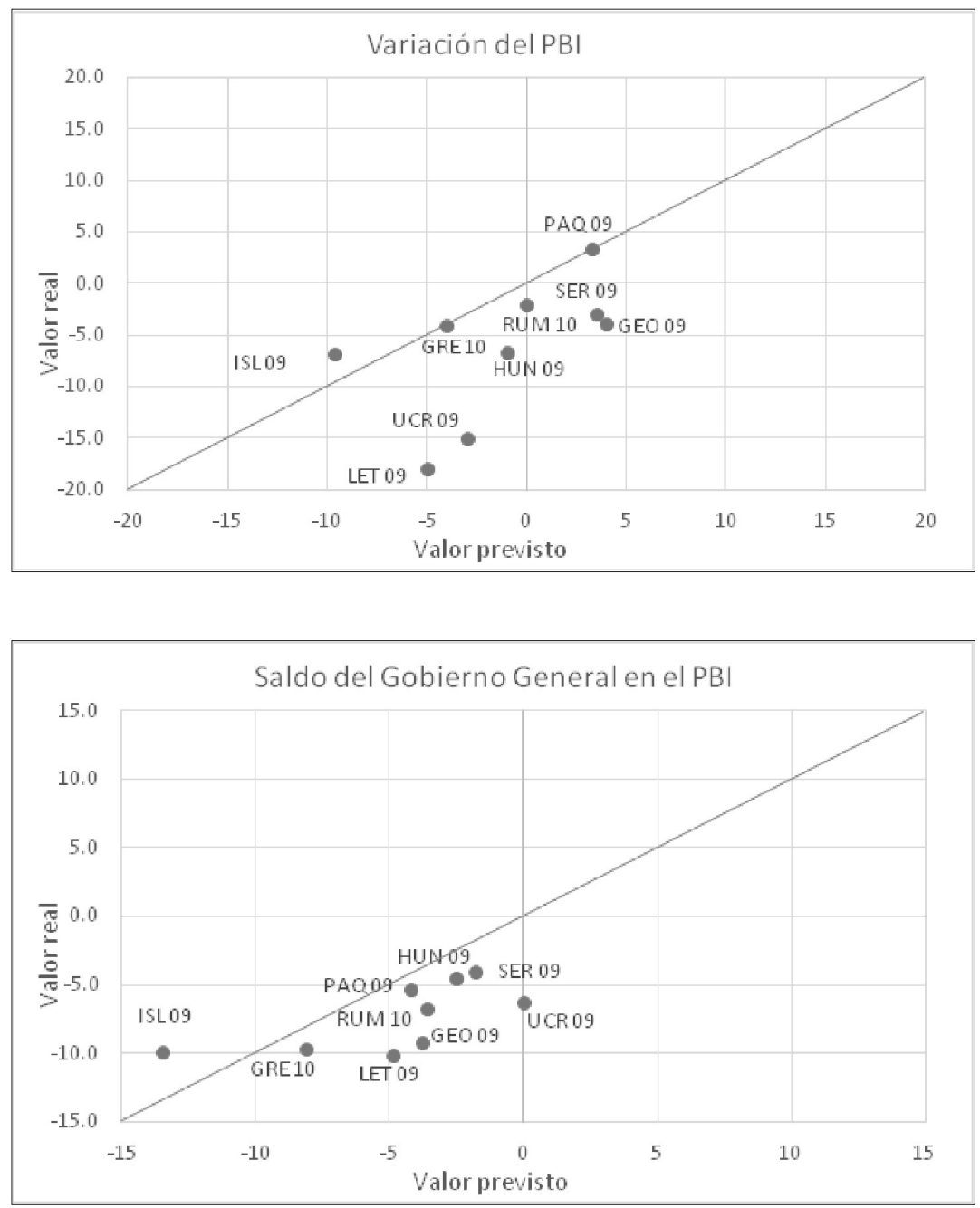


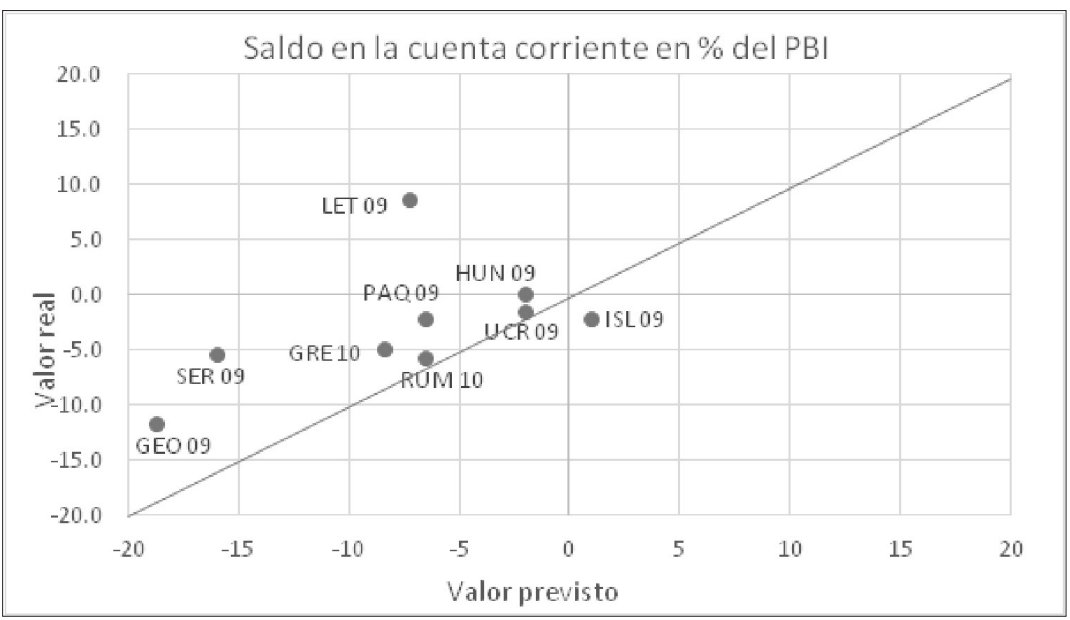

Fuente: FMI. Los países considerados son Georgia, Grecia, Hungría, Islandia, Letonia, Paquistán, Rumania, Serbia y Ucrania. Los años son los que siguen a la firma del ASB.

Gráfico 3. Previsiones y resultados para variables macroeconómicas clave en Acuerdos Stand By, firmados entre 2012 y 2018, países escogidos

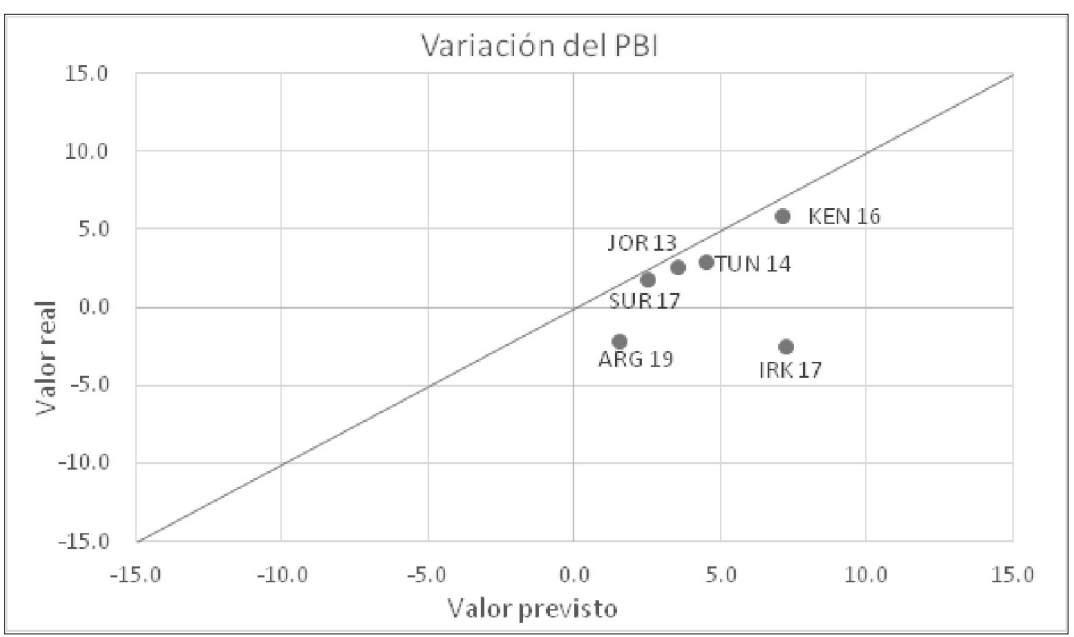



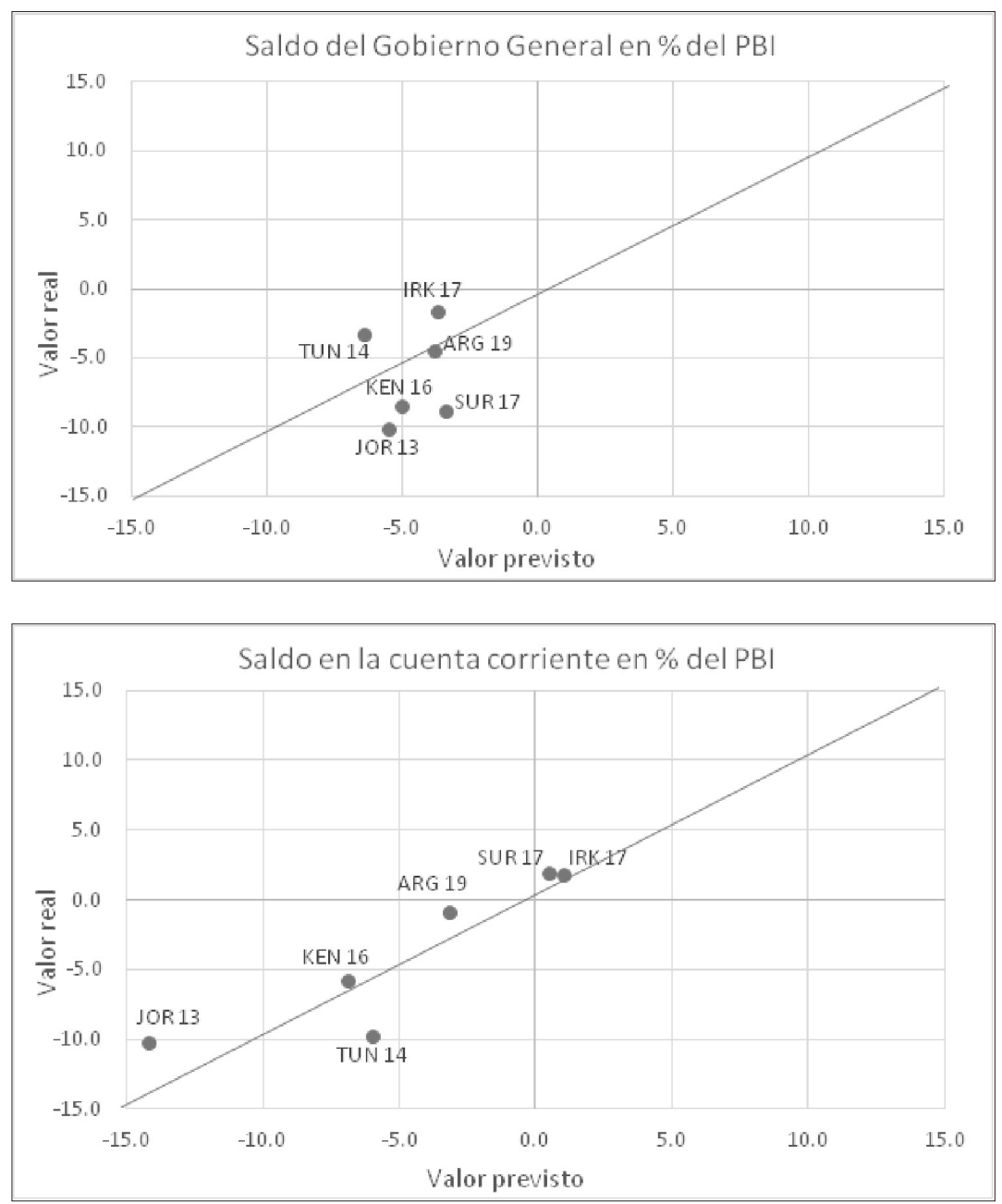

Fuente: FMI. Los países considerados son Argentina, Irak, Jordania, Kenia, Surinam y Túnez. Los años son los que siguen a la firma del ASB.

El gráfico 1 compara las previsiones del FMI con los resultados reales en un grupo de países afectados por la crisis de fines de los noventa. Se observa que, en casi todos los casos, las observaciones se encuentran por debajo y a la derecha de la línea de $45^{\circ}$; esto indica que los valores predichos fueron más optimistas que los que tuvieron lugar en la realidad, en algunos 
casos por un elevado margen. Así, el FMI preveía, para 1998, un crecimiento de $5 \%$ en Indonesia, que en realidad se contrajo un $13 \%$. Se anticipaba un crecimiento de 3,5\% para Tailandia en 1998, pero cayó 10,5 \%. La Argentina iba a crecer 3,7 \% en 2001 según el FMI, pero cayó un 4,4\%. Etcétera. El único país cuyo desempeño fue superior al anticipado por el FMI fue la Federación Rusa (creció 6,4 \% en 1999, en lugar del 1 \% previsto), pero se trata de un país que incumplió con sus compromisos asumidos en el ASB - en efecto, declaró una moratoria para su deuda externa-.

También se constata un sesgo sistemático en las previsiones fiscales: aquí también, en casi todos los casos, tales previsiones pecaron por su optimismo. Indonesia y Tailandia experimentaron déficits en vez los excedentes anticipados, y en la mayor parte de los demás países, el déficit real superó con mucho al pronosticado. En cambio, se verifica el sesgo contrario para los saldos en la cuenta corriente de la balanza de pagos. Países para los que se predecía un déficit, como Tailandia, Rusia y Corea, tuvieron cuantiosos excedentes (superiores a $10 \%$ del PBI), y en Argentina y Turquía, el déficit fue muy inferior al anticipado.

En ocasión de la crisis de 2008-2009, se observan los mismos sesgos (Gráfico 2). La gran mayoría de los países que recurrieron al FMI experimentaron, al año siguiente, tasas de crecimiento inferiores a las pronosticadas: Ucrania cayó un $15 \%$ en vez del $3 \%$, Letonia se contrajo un $18 \%$, en lugar del $5 \%$ que se había previsto. Por su parte, Serbia y Georgia sufrieron caídas del PBI, pese a que se esperaban sendos crecimientos. Los pronósticos fueron certeros para Grecia y Paquistán, y sólo Islandia se encuentra "por encima" de la línea de $45^{\circ}$, porque allí la contracción económica (-6,8 \%) fue inferior a la anticipada por el FMI (-9,6\%). Pero aquí también se trata de un país que no respetó los compromisos que asumió en el ASB.

Asimismo, se repite el sesgo en los resultados fiscales: todos los países considerados (menos Islandia) registraron un déficit mayor al programado (por ejemplo, fue de $10 \%$ del PBI 
en Letonia, el doble del que fue predicho). Y también todos los países tuvieron un desequilibrio en la cuenta corriente menor al que había estimado el Fondo (de nuevo, con la excepción de Islandia). Letonia llegó a tener un excedente de 8,6 \% del PBI, en lugar de un déficit de 7,3\%.

Estos sesgos se moderan en los siguientes ASB, pero no desaparecen (Gráfico 3). Allí vemos que Túnez y Kenia crecen menos que lo anunciado, Argentina e Irak sufren una contracción del PBI en lugar del crecimiento que se anticipaba, mientras que, en Jordania y Surinam, se verificó un crecimiento similar al previsto. El saldo fiscal verificado fue, nuevamente, peor que el estimado en todos los países menos Irak y Túnez, y el saldo en cuenta corriente resultó mejor que el proyectado, excepto en Túnez.

\section{c. La experiencia reciente de la Argentina}

El caso argentino merece una mención aparte, por tratarse del Acuerdo Stand By que comprometió el monto más elevado en la historia del FMI, y también uno de los que fracasó con mayor rapidez. A partir de diciembre de 2015, el gobierno había sostenido políticas macroeconómicas inconsistentes mediante la emisión acelerada de deuda pública, principalmente externa: entre el primer trimestre de 2016 y el mismo trimestre de 2018, el Gobierno General colocó 76 mil millones de dólares de deuda externa neta y el Banco Central otros 9 mil millones. Cuando aumentó la percepción de riesgo y se frenó el acceso fácil a los capitales externos privados, el gobierno acudió al FMI. El Acuerdo Stand By de junio de 2018 se presentó como una medida de precaución. El elevado monto del financiamiento aprobado (50 000 millones de dólares, luego ampliado a 57000 millones) debía alejar cualquier riesgo de default y, junto a la vigilancia del propio FMI, restablecer la confianza en la política económica. Con la confianza regresaría el financiamiento privado, y con este el crecimiento económico, y la reelección del presidente Macri. En efecto, desde un principio quedó claro que 
las facilidades excepcionales que el FMI concedió a la Argentina respondían a ese fin político. No solamente se entregaba un crédito por casi 13 veces la cuota del país (un ASB permite normalmente acceder a un máximo de 4,35 veces la cuota del país), sino que un $88 \%$ de este debía desembolsarse antes de las elecciones de octubre de 2019.

Se esperaba que la intervención del FMI reordenaría la política macroeconómica. De hecho, el FMI reprodujo sus condiciones habituales de austeridad fiscal y restricción monetaria, y juzgó necesario dejar depreciarse la moneda. En efecto, el Banco Central estaba perdiendo reservas para defender la cotización del peso, lo que (en un primer momento) el FMI estimaba desacertado, en vista del déficit en la cuenta corriente de la balanza de pagos. La devaluación dio un nuevo impulso a la inflación, que se mantenía muy por encima de las metas del Banco Central, a lo que este respondió con nuevos aumentos de la tasa de interés y el compromiso de no aumentar la base monetaria. La tasa de interés que pagaban las letras del Banco Central pasó de un ya elevado 2,8 \% mensual en mayo de 2018 a 3,8 \% en agosto, para establecerse entre 5 y $6 \%$ en el último trimestre de 2018 y buena parte de 2019. En septiembre de ese año superó el $7 \%$. Se trata de valores anuales superiores a $100 \%$. Las tasas activas que debían pagar las familias (tarjetas de crédito) y las pequeñas empresas eran aún mayores. Este costo del crédito, que se compara con una inflación de $55 \%$, tuvo un efecto devastador sobre la solvencia de las empresas, la actividad económica y las cuentas públicas. Por su parte, el gobierno anunciaba la meta de "déficit cero" para el balance fiscal primario, para lo cual redujo su gasto en todos los rubros menos el pago de intereses. De este modo, agravó aún más la recesión económica.

Estas políticas procíclicas profundizaron la recesión en vez de mitigarla: el PBI se contrajo un 2,6 \% en 2018 y 2,1\% en 2019 , frente a las predicciones iniciales de un crecimiento de $0,4 \%$ y $1,5 \%$ para esos años. Por otra parte, la austeridad 
fiscal no equilibró las cuentas públicas, debido a la contracción de los ingresos fiscales en términos reales. Además, la carga creciente de intereses sobre las cuentas fiscales compensaba en gran medida la reducción del gasto primario. Así, el déficit del gobierno general fue de 5,8 \% del PBI en 2018 y 4,3\% en 2019, frente a las predicciones de 5,1\% y 3,8 \% del PBI, respectivamente. ${ }^{28}$ Por otra parte, la contracción monetaria no frenó la inflación, evidenciando el error de diagnóstico que supone tratar de reducirla mediante la disminución de la demanda, cuando la economía ya está en recesión. Pero, además, ni siquiera esas tasas de interés lograron frenar la salida de capitales. En suma, las políticas no solamente resultaron costosas desde el punto de vista social, sino que fueron inefectivas desde el económico.

Con el fin de contener una devaluación del peso que contrariaría sus chances electorales, el gobierno recurrió entonces a las reservas internacionales que había acumulado durante los dos primeros años, a las que se sumaron los préstamos del FMI (los desembolsos alcanzaron los 44000 millones de dólares). De este modo, el Acuerdo Stand By del FMI no consiguió encauzar la actividad económica ni revertir la salida de capitales privados: el sector privado no financiero adquirió activos externos por 58000 millones de dólares y canceló pasivos de cartera por 9000 millones de dólares; estos montos se suman a la salida de capitales privados no financieros por 31000 millones de dólares entre 2016 y el primer trimestre de 2018, redondeando casi 100000 millones de capital privado fugado en cuatro años. ${ }^{29}$

\footnotetext{
28 El resultado fiscal sería mucho peor si se incluyera el pago de intereses por parte del Banco Central (3 \% del PBI en 2019) y no se registrara como ingresos la venta de activos financieros en manos de agencias públicas (0,5\% del PBI en 2019), que debiera computarse como financiamiento.

29 Fuente: INDEC, Estadísticas integradas de balanza de pagos, posición de inversión internacional y deuda externa, años 2006-2020, en https://www.indec.gob.ar/indec/web/ Nivel4-Tema-3-35-45. Para un análisis pormenorizado de la fuga de capitales durante la administración de Macri, véase Banco Central de la República Argentina, "Mercado de cambios, deuda y formación de activos externos 2015-2019", en http://www.bcra.gov.ar/ Noticias/publicacion-de-informe-mercado-cambios-deuda-2015-2019.asp.
} 
Vemos así que el FMI aportó las divisas necesarias para materializar la salida de capitales (proceder que es contrario al artículo VI de su Convenio Constitutivo). Al avalar la infracción a una de sus reglas fundamentales, el FMI se involucraba aún más en la política interna de la Argentina, apoyando a un candidato más que a un país.

\section{d. Las razones de los sesgos}

La repetición de errores, siempre con el mismo sesgo, y en muchos casos de gran magnitud, puede en parte explicarse por motivos de conveniencia política: los gobiernos y la opinión pública de los países estarán mejor dispuestos a aplicar políticas pro-cíclicas si, en su presentación, se minimiza el costo futuro en términos de actividad económica. Asimismo, el Directorio del FMI aprobará con mayor facilidad un programa si el staff técnico anuncia un ajuste fiscal exitoso y la pronta recuperación del crecimiento, factores clave para la sustentabilidad de la deuda. Un ejemplo de ese tipo de sesgo, motivado por razones políticas, lo brinda el ASB de Argentina de 2018, como acabamos de ver. Una evaluación más objetiva por parte del staff técnico y previsiones económicas más realistas que las que aquél avanzó, hubieran llevado a negar el acceso excepcional de recursos que se otorgó a Argentina, ya que se hubiera constatado que ese caso no reunía los criterios necesarios para otorgar tal acceso; ${ }^{30}$ ahora bien, eso habría contrariado la voluntad del país miembro más influyente del FMI (a quien los niveles más altos de su gerencia obedecían), quien quería aprobar ese programa por razones geopolíticas. ${ }^{31}$

\footnotetext{
30 Fondo Monetario Internacional, "IMF Executive Board Approves Exceptional Access Lending Framework Reforms", 16/XX Press Release, 28 de enero de 2016.

31 Explicaciones de Mauricio Claver-Carone ante el Consejo Chileno para las Relaciones Internacionales, reproducidas por Román Lejtman en Infobae del 28 de julio de 2020. ClaverCarone era el director ejecutivo en el FMI representando a los EE. UU. cuando se aprobó el ASB. Hoy preside el Banco Interamericano de Desarrollo.
} 
Sin desechar la incidencia de consideraciones políticas, la existencia de sesgos tan persistentes, generalizados y significativos evidencian la inadecuación de la visión teórica y de los instrumentos analíticos del FMI. La tendencia a subestimar el costo económico de sus programas de ajuste es consistente con la concepción ortodoxa que supone la existencia de una ágil compensación (trade-off) entre el gasto público y el gasto privado. De acuerdo con esa visión, una disminución del gasto público (con la correspondiente reducción de la emisión monetaria) liberaría recursos utilizables por el gasto privado, cuyo aumento compensaría el efecto recesivo del ajuste fiscal. Más aún, una "consolidación fiscal" devolvería confianza a los mercados financieros, que de ese modo volverían a abrir las líneas de financiamiento. Así, se consolidaría tanto la reactivación económica del país en cuestión como la sustentabilidad de su deuda. ${ }^{32}$

En realidad, este enfoque subestima el costo económico de las políticas de ajuste recesivo practicadas durante una recesión, y no justifica por qué en tales circunstancias las empresas privadas tomarían el relevo del gasto público y expandirían su inversión. Al sobreestimar el crecimiento del PBI, también sobreestima los ingresos tributarios, lo cual explica en buena medida que los técnicos del FMI y de los gobiernos nacionales hayan incurrido en el mismo sesgo excesivamente optimista en lo que hace al crecimiento del PBI y al resultado fiscal (Gráficos 1 a 3). En cambio, existe la tendencia a subestimar el ajuste en la balanza de pagos. Un menor nivel de actividad económica respecto del proyectado viene de la mano con un menor nivel de importaciones, lo cual contribuye a reequilibrar la cuenta corriente (o volverla superavitaria) mucho antes de lo previsto.

También se comprobó, por parte de los técnicos del FMI, una incomprensión de las dinámicas financieras. La fijación de tasas de interés muy elevadas por períodos prolongados afecta

\footnotetext{
32 Se ha mostrado cómo, en sus evaluaciones de la deuda soberana, las agencias calificadoras de riesgo siguen esta visión ideológica más que un análisis objetivo; véase UNCTAD, Trade and Development Report 2015, (Nueva York y Ginebra, 2015), 106 y 107.
} 
el balance de las empresas, que por otra parte experimentan una contracción de sus ventas. De este modo, no solamente se ven en la imposibilidad de compensar con sus inversiones los recortes en el gasto público, sino que muchas de ellas enfrentan situaciones de insolvencia. Del mismo modo, la devaluación de la moneda deteriora el balance de los agentes con endeudamiento neto en moneda extranjera. En tal situación, las restricciones monetarias dictadas por el FMI (que afectaron la provisión de financiamiento del Banco Central) tendieron a precipitar o agravar las crisis bancarias.

Estos resultados muestran que, en muchos casos, el FMI propugnó políticas excesivamente restrictivas, que resultaron más costosas de lo previsto en términos de actividad y, por lo tanto, también de empleo e ingresos de la población. Tal sobreajuste fue ineficiente desde el punto de vista de la consolidación fiscal, e innecesario desde la perspectiva del ajuste externo, ya que con un costo en términos de crecimiento significativamente menor se hubiera podido alcanzar las metas externas contenidas en los ASB.

\section{5. ¿Hacia una revisión del papel del FMI?}

Decíamos en la introducción que el FMI nació bajo un doble influjo: primero, la voluntad de establecer y regular un sistema monetario, financiero y cambiario estable, que favoreciera la expansión del comercio internacional y permitiera el ajuste de los desequilibrios con los menores costos posibles para los países afectados y la comunidad internacional. El segundo era la hegemonía de los Estados Unidos. Repasaremos a continuación cómo se sitúa hoy el FMI en estos dos planos.

\section{a. Cuestionamientos generalizados y reposicionamientos parciales}

En las páginas anteriores, constatamos que, en gran medida, el FMI no está cumpliendo con su rol primario. Desde hace ya 
medio siglo que no consigue evitar la repetición de desequilibrios y crisis financieras y cambiarias de grandes dimensiones. A esto se agrega que, en vez de suavizar las crisis y moderar sus costos económicos y sociales, ha introducido un sesgo pro-cíclico en sus programas de asistencia crediticia. De este modo, "a través de su condicionalidad, el Fondo ha impuesto en los hechos exactamente el tipo de políticas que los planificadores de posguerra querían evitar en los países que enfrentaban problemas de pagos, austeridad y ajustes cambiarios desestabilizadores". ${ }^{33}$ Tales políticas, como vimos, eran no solamente costosas sino, con frecuencia, ineficaces.

El FMI (o, más precisamente, algunos de sus economistas) recogió algunas de esas críticas, y reconoció algunos errores. En particular, admitió que las medidas fiscales restrictivas que impulsó después de la crisis de 2008-2009 resultaron más costosas de lo que había anticipado, porque, durante las recesiones, el efecto multiplicador del gasto público era mayor al que estimaba; es decir, una restricción fiscal contraía la actividad en mucho mayor medida que lo que había calculado con anterioridad. ${ }^{34}$ También reconoció que, en determinadas circunstancias, puede ser necesario adoptar medidas para "administrar" los flujos de capital (se evita la palabra "controlar"). ${ }^{35}$ Por último, hubo una reevaluación de las políticas monetarias, en la que los autores cuestionan la anterior ortodoxia por la cual los bancos centrales debían proseguir un único objetivo (las metas de inflación) con un solo instrumento (la tasa de interés). Era factible ahora considerar otros objetivos, tales como la actividad económica y la estabilidad financiera, y otros instrumentos además de la tasa de interés, tales como el control de capitales y el uso

33 Yilmaz Akyüz, "Reforming the IMF: Back to the drawing board". G-24 Discussion Paper Series No. 38, noviembre de 2005.

34 Olivier Blanchard y Daniel Leigh, "Growth forecast errors and fiscal multipliers", IMF Working Paper WP/13/1, enero de 2013.

35 Fondo Monetario Internacional, "The liberalization and management of capital flows: an institutional view." (Washington D.C., noviembre de 2012). 
contracíclico de la regulación bancaria (por ejemplo, a través de coeficientes de capitalización variables). ${ }^{36}$

Todos estos puntos serían importantes si se los llevara a la práctica, es decir, si se tradujeran en cambios en las políticas que el FMI impulsa. Por ahora, esto no ha ocurrido, en parte porque los mismos autores de estas revisiones no han extraído todas las enseñanzas de sus observaciones. Así, sugieren limitar la administración de los capitales externos a situaciones de crisis de balance de pagos, es decir, cuando ya es tarde para prevenir los efectos desestabilizadores de los flujos de capital. ${ }^{37}$ En cuanto a las políticas fiscales contracíclicas (que deberían estimular la economía durante las recesiones, además de proteger a la población más vulnerable), el FMI tiende a recomendarlas solamente para los países que cuentan con "espacio fiscal", lo que no es el caso, precisamente, de los que recurren a él. Por último, observamos que el control de la inflación sigue siendo el objetivo central, por no decir excluyente, de las políticas monetarias que el FMI propugna, y que estas aplican sus instrumentos habituales (tasa de interés y emisión de base monetaria) con la misma tradicional dureza. ${ }^{38}$

A las medidas macroeconómicas se agregan las reformas estructurales que el FMI ha buscado imponer en ocasión de sus programas. Como explicaba con total transparencia Michel Camdessus, entonces director gerente del Fondo, "Intervenimos de manera más decisiva, naturalmente, cuando un país sufre

\footnotetext{
36 Véase Olivier Blanchard, Giovanni Dell'Ariccia y Paolo Mauro, "Rethinking macro policy: getting granular", IMF Staff Discussion Note SDN/13/03, abril de 2013. Los autores evalúan la posibilidad de incluir una determinada tasa de cambio como objetivo y la intervención del Banco Central en el mercado cambiario como instrumento, pero estiman que hay factores políticos que hacen que tal ampliación de la política monetaria y cambiaria no sea aceptable.

37 En la Argentina, se levantaron todas las limitaciones a la entrada de capital en diciembre de 2015, lo que alimentó el sobreendeudamiento, y recién se impuso un límite estricto a la compra de dólares por los particulares después de realizadas las elecciones presidenciales de octubre de 2019.

38 Una vez más el programa recientemente aplicado en la Argentina ilustra a qué extremos pueden llegar las políticas monetarias restrictivas de un ASB.
} 
una aguda crisis en su balanza de pagos y nos pide ayuda para hacer frente a esa situación. Entonces, tratamos de aprovechar esa crisis para conseguir una mejora duradera, esforzándonos por llegar a la raíz de los problemas". ${ }^{39}$ O, como reza la frase atribuida a Winston Churchill, "nunca desaproveches una buena crisis". Es el momento en el cual el país afectado tiene menor poder de negociación, y un organismo como el FMI, manejado por los países desarrollados más poderosos, puede atacar "la raíz de los problemas" con el criterio que le es propio: las reformas neoliberales identificadas con el Consenso de Washington, que enumeramos en el punto 3.

El FMI avanzó con decisión por ese camino. Después de haber impulsado, a partir de la crisis de la deuda de los años ochenta, las reformas neoliberales en América Latina, buscó aprovechar la crisis asiática de 1997-1998 para remodelar las economías de los países afectados (atendiendo no pocas veces los intereses de países influyentes en el Directorio del FMI), ${ }^{40}$ incidió de manera decisiva en el rediseño de las economías anteriormente socialistas, y fue funcional a las reformas que querían aplicar los países europeos más poderosos en los países de la periferia de la Unión Europea, en ocasión de la crisis financiera iniciada en 2008.

39 Michel Camdessus, "Los elementos claves de los programas de ajuste estructural", Contribuciones CIEDLA, octubre-diciembre de 1991, Buenos Aires, 12.

40 El FMI Ilegó a formular 140 condiciones estructurales para Indonesia (en su programa de junio de 1998), 94 para la República de Corea (noviembre de 1999) y 73 para Tailandia (mayo de 1998). En Corea, algunas de esas condiciones se referían a la flexibilización laboral, así como a la privatización y extranjerización de bancos, autorizándose la entrada de capital extranjero en las empresas nacionales; asimismo, el país se vio forzado a liberalizar su comercio y flujo de capitales, y a otorgar una serie de concesiones a los EE. UU. y al Japón, a las que Corea se había negado anteriormente en el seno de la OMC. En Indonesia se impuso el cierre de 16 bancos como "acción preliminar" (prior action) de cualquier programa; las condiciones estructurales que siguieron eliminaron la limitación a la inversión extranjera en compañías locales y en sectores de los que estaba anteriormente excluida; forzaron al Banco de Indonesia a vender sus acciones en bancos privados, suprimieron restricciones a la apertura de sucursales de bancos extranjeros y a la inversión extranjera en los bancos locales e impulsaron la privatización de bancos públicos; asimismo, redujeron una serie de tarifas aduaneras, suprimieron restricciones a las importaciones y desregularon el mercado de productos alimenticios, entre muchas otras medidas. 
Semejante ejercicio del poder del FMI confirmaba los análisis según los cuales este "sirvió como instrumento de política exterior del Tesoro de Estados Unidos más que como estabilizador de la economía mundial". ${ }^{41}$ Crecieron los cuestionamientos a la legitimidad de imponer reformas estructurales en el contexto de negociaciones asimétricas entre países con problemas de pagos y el (casi) único posible proveedor de fondos que les quedaba. Para algunos críticos, la condicionalidad estructural excedía el mandato y las competencias del FMI, y debía ser eliminada. ${ }^{42}$ Dentro del propio FMI, se reconoció que "existen preocupaciones legítimas de que en varias ocasiones la condicionalidad estructural fue más allá de lo que el propósito de salvaguardar los recursos del Fondo mediante la condicionalidad puede justificar". ${ }^{43}$ Más aún, la Oficina de Evaluación Independiente del FMI afirmó que "las crisis no deberían ser usadas como una oportunidad para aplicar una larga agenda de reformas con un cronograma detallado solo porque el poder de presión es elevado, aun cuando tales reformas puedan ser beneficiosas para la eficiencia económica de largo plazo". ${ }^{44}$

El FMI reaccionó con la formulación de nuevas orientaciones para su condicionalidad. En ellas se reafirman el principio de la "propiedad nacional" de los programas, según el cual estos son propios a los gobiernos de cada país, y no una imposición de parte del organismo; y el principio de su "parsimonia", lo que reduciría el número de condiciones en cada programa. ${ }^{45}$

\footnotetext{
41 Oscar Ugarteche, Arquitectura financiera internacional: una genealogía de 1850-2008, (Universidad Nacional Autónoma de México, México D.F., 2014), 296.

42 Véase Akyüz, op. cit., 6.

43 Fondo Monetario Internacional, "Conditionality in Fund-supported programs - Policy issues". Preparado por el Departamento de Elaboración y de Examen de Políticas, Washington D.C., (16 de febrero de 2001), 27.

44 Oficina de Evaluación Independiente del FMI, "The IMF and recent capital account crisis: Indonesia, Korea, Brasil." Evaluation Report, (Washington D.C., 28 de julio de 2003), 50.

45 Véase FMI, “Guidelines on conditionality", Preparado por el Departamento Jurídico y el Departamento de Elaboración y Examen de Políticas, (25 de septiembre de 2002).
} 
En 2009, eliminó un tipo de condicionalidad, la referida a los "criterios de desempeño estructural" (Structural performance criteria), quedando sin embargo la posibilidad de fijar "metas estructurales" (Structural benchmarks). La diferencia consiste en que el hecho de no cumplir con estas últimas no lleva de manera automática a interrumpir los desembolsos del fondo, como ocurre con los criterios de desempeño (cuantitativos o estructurales); la decisión queda, empero, a criterio del Directorio; es decir, de los gobiernos de un pequeño número de países desarrollados.

\section{b. Debe revisarse el funcionamiento del FMI para que respete los derechos humanos}

El FMI pertenece, formalmente, al sistema de las Naciones Unidas. Sin embargo, un número limitado de países desarrollados ejerce su control efectivo, en tanto la mayor parte de sus miembros tienen un peso marginal, tanto en el poder de voto como en el Directorio Ejecutivo. Esta asimetría entre los distintos países miembros plantea un problema, no solamente para la legitimidad de las decisiones referidas a la gestión del sistema monetario y financiero internacional, sino muy especialmente cuando se diseñan las políticas coyunturales y de desarrollo de los países que solicitan la asistencia del FMI.

Lo que está en juego aquí es, ni más ni menos, el respeto de la democracia en los países miembros del FMI: qué calidad democrática tienen las decisiones que se toman bajo la presión ejercida por una institución que no ha sido electa por la población del país, y cuyo control está en manos de los gobiernos de un puñado de países desarrollados que reúnen apenas un 13,5 \% de la población mundial. El principio de la "propiedad nacional" de los programas ya existía antes de las "nuevas orientaciones" de 2002, pero no impidió en aquel entonces las presiones sobre los gobiernos de los países miembros, como no parece estar haciéndolo ahora.

Además, como hemos visto, el contenido de los programas macroeconómicos y estructurales tienden a concentrar (y 
extranjerizar) el ingreso y la propiedad, y a profundizar de manera innecesaria las recesiones económicas, con un impacto inevitable sobre el nivel de vida de la población.

Hay entonces dos niveles en donde, a nuestro entender, el FMI ha incumplido (y sigue violando) la Declaración Universal de los Derechos Humanos de las Naciones Unidas: el primero es arrogarse parte de la autoridad del poder público de un país, que debe residir en la voluntad de su pueblo (artículo 21 de la Declaración). El segundo es agravar con políticas de ajuste recesivo las situaciones críticas en las que interviene y desviar una parte sustancial de los recursos de que disponen los Estados que, en vez de utilizarse en la realización de los derechos económicos, sociales y culturales (art. 2 del Pacto Internacional de Derechos Económicos, Sociales y Culturales), ${ }^{46}$ se dedican al pago de servicios financieros. ${ }^{47}$ De ese modo, se atenta en contra del acceso al trabajo con una remuneración que asegure una existencia digna a las familias, y también contra el acceso al bienestar, la vivienda, la cultura, así como los servicios públicos de salud, educación y los servicios sociales que se ven afectados por las políticas de ajuste contractivo que hemos analizado (artículos 23 a 27 de la Declaración). Así como "toda persona tiene derecho a que se establezca un orden social e internacional en el que los derechos y libertades proclamados

46 Art. 2: "Cada uno de los Estados Partes en el presente Pacto se compromete a adoptar medidas, tanto por separado como mediante la asistencia y la cooperación internacionales, especialmente económicas y técnicas, hasta el máximo de los recursos de que disponga, para lograr progresivamente, por todos los medios apropiados, inclusive en particular la adopción de medidas legislativas, la plena efectividad de los derechos aquí reconocidos" (énfasis agregado por el autor).

47 Tal acción vulnera los "Principios rectores relativos a las evaluaciones de los efectos de las reformas económicas en los derechos humanos" de las Naciones Unidas, a ser observados por los gobiernos, las instituciones financieras internacionales y los acreedores, en particular el principio núm. 9 que llama a que las políticas fiscales, tributarias, de deuda, comerciales, de ayuda, monetarias y ambientales estén dirigidas a la realización de los derechos humanos. Los principios, presentados en el $40^{\circ}$ período de sesiones del Consejo de Derechos Humanos (del 25 de febrero al 22 de marzo de 2019) están disponibles en: https:// www.undocs.org/es/A/HRC/40/57. 
en esta Declaración se hagan plenamente efectivos" (artículo 28), los países miembros tienen la tarea de adecuar con tales fines el funcionamiento del FMI.

Asimismo, dado que los bancos centrales son también actores estatales, tienen obligaciones en materia de derechos humanos. ${ }^{48}$ Por ello, el FMI no debería forzarlos ni apoyarlos a incumplirlas en la implementación de políticas cambiarias y monetarias con efectos adversos sobre los derechos de la población.

El FMI debe realmente regular el SMFI, para evitar los desequilibrios y las crisis periódicas; debe servir como prestamista en última instancia para los países, dando muestras de mayor flexibilidad y sin una condicionalidad que vulnere sus soberanías y el bienestar de su población; y debe retomar la idea keynesiana de distribuir el esfuerzo del ajuste entre países deficitarios y excedentarios, para eliminar el sesgo recesivo que introduce hoy en la economía mundial.

La reorientación de la forma en que funciona una institución no puede sino ser el resultado de un proceso político, que a su vez depende de la relación de fuerzas existente. Recordamos que fue la hegemonía norteamericana de posguerra la que determinó que se escogiera el proyecto defendido por White en lugar del propuesto por Keynes. Y dentro de ese ordenamiento, se les otorgó a los Estados Unidos y a los países desarrollados las cuotas y el poder de voto más importantes.

Esas cuotas reflejan diversas variables económicas (participación en el PBI mundial en valores corrientes y en paridad

48 Daniel Bradlow, "Why central banks need to take human rights more seriously", Open Democracy, 9 de julio de 2019, disponible en https://www.opendemocracy.net/en/oureconomy/ why-central-banks-need-take-human-rights-more-seriously/; Motoko Aizawa, Daniel Bradlow y Margaret Wachenfeld, "International Financial Regulatory Standards and Human Rights: Connecting the Dots", Manchester Journal of International Economic Law, 2018, Vol. 15, 2-44; y Principios Rectores cit., Numeral 11.7: "Los bancos centrales son instituciones del Estado y, como tales, tienen la obligación de cumplir el derecho y las normas internacionales de derechos humanos. Los objetivos de inflación y empleo, entre otros, deben estar en consonancia con las obligaciones del Estado en materia de derechos humanos a fin de evitar cualquier medida regresiva inadmisible". 
de poder de compra, participación en el comercio mundial, proporción de las reservas internacionales y un indicador de "volatilidad" que remite a la participación en los flujos de capitales), que como su nombre lo indica, no permanecen fijas. Es por eso que los estatutos del Fondo establecen que cada 5 años debe revisarse, y eventualmente modificarse, la distribución de cuotas y derecho a voto, según cómo hayan evolucionado las variables mencionadas. Esa revisión debió ocurrir en 2016. Se hicieron los cálculos, que indicaban una disminución de la cuota de Estados Unidos desde 17,4 \% a 14,7 \% del total, un aumento de la cuota China desde $6,4 \%$ a $12,9 \%$, y una disminución generalizada de las cuotas de los países desarrollados. Así, estos debían pasar de 57,7 \% a 50,4\%, frente a 49,6 \% de los subdesarrollados y "emergentes". Al pasar por debajo de $15 \%$, los EE. UU. perderían el poder de veto que actualmente ejercen en todas las decisiones que requieren de una mayoría especial de $85 \%$ de los votos. El cambio en las cuotas y una modificación del Convenio Constitutivo del FMI requieren esa mayoría.

Es incierto cuánto tiempo la actual dirección del FMI seguirá sin observar las reglas que la obligan a reexaminar las cuotas cada 5 años: ya van 10. Lo que no ofrece duda alguna es que, si se aplicara la fórmula existente a los actuales valores del PBI, comercio, etc., los países en desarrollo pasarían a tener una mayoría de los votos, y la cuota de China superaría a la de los Estados Unidos. Sería el momento adecuado para reformar esa institución, su funcionamiento y su ideología, incorporando a un staff que provenga de otras experiencias y de universidades que no sean siempre las anglosajonas, que dominan, de manera abrumadora, en la actualidad. También será necesario mudar la sede desde Washington hacia alguna ciudad china, en cumplimiento del artículo XIII, Sección 1, del Convenio Constitutivo del FMI: "La sede del Fondo estará situada en el territorio del país miembro que tenga la cuota mayor y se podrán establecer dependencias u oficinas en los territorios de otros países miembros". 
La reforma radical del FMI sería un paso importante en la construcción de un orden internacional multilateral, basado en principios y respetuoso de los derechos humanos, en el cual el Fondo podría evolucionar desde el esquema actual de cuotas hacia un modelo de "banco central mundial". Semejante paso enfrentaría grandes dificultades, ya que los países hoy dominantes dentro de la estructura del FMI pueden obstaculizar el proceso de reformas, e incluso desconocer las reglas que ellos mismos fijaron cuando dejan de serles favorables. Pero en tal caso, el FMI perderá lo que le queda de legitimidad, y es probable que se transite hacia un sistema multipolar, con una pluralidad de monedas internacionales y acuerdos regionales e interregionales ad boc.

\section{Conclusiones}

El FMI fue creado con el objetivo loable de organizar un Sistema Monetario y Financiero Internacional estable, que favoreciera el comercio internacional, y que fuera capaz de corregir los desequilibrios con el menor costo posible, tanto para los países deficitarios como para el conjunto de la economía mundial. Para llevar a cabo estos objetivos, se le confirió al FMI poderes de supervisión sobre las políticas monetarias y cambiarias de los países miembros, y la potestad de incidir sobre tales políticas en ocasión de los programas de asistencia que firma con los países en dificultades.

Este trabajo analiza las políticas monetarias y cambiarias que el FMI ha impulsado en su historia. Procura mostrar que tales políticas tienen una incidencia determinante en el desempeño económico de los países, y que con frecuencia esa incidencia es negativa. Son parte, de manera general, de políticas procíclicas que agravan las recesiones en los países deficitarios, en tanto no se requiere a los países excedentarios que contribuyan, con políticas expansionistas, a absorber los desequilibrios en las balanzas de pagos. Guiadas por teorías económicas cuestionables, las políticas propugnadas por el FMI han agravado tanto 
la inestabilidad económica y financiera internacional como el costo económico y social de las crisis resultantes. Esto ha ido en detrimento del respeto por los derechos económicos, sociales y culturales de las personas que habitan los países afectados.

Los efectos de las políticas impulsadas por el FMI han motivado numerosas críticas, que, aunque de manera muy parcial y en el plano teórico, esa institución ha aceptado. Sin embargo, no se observa un cambio en las políticas que aplica en sus programas crediticios. El caso del reciente programa fallido de la Argentina muestra la continuidad de las antiguas políticas de ajuste recesivo, además del uso de los recursos del FMI, no en función de las necesidades de los países miembros en dificultades y de sus habitantes, sino de los intereses geopolíticos de los países que lo controlan.

Con este funcionamiento y con sus recomendaciones, el FMI viola o induce a los Estados a vulnerar numerosos derechos establecidos en la Declaración Universal de Derechos Humanos de las Naciones Unidas, el Pacto Internacional de Derechos Económicos, Sociales y Culturales, así como los principios rectores que tanto los Estados como las instituciones internacionales deberían observar al momento de aplicar reformas económicas, para realizar esos derechos humanos.

Una reforma profunda del FMI resulta necesaria, tanto para corregir estas graves deficiencias como para adaptar la institución a las nuevas realidades económicas y políticas: la actual organización del FMI y la distribución del poder de decisión en la institución reflejan una relación de fuerzas (la de mediados del siglo pasado) que ya no existe. De la capacidad que tenga el FMI para adaptarse a la nueva situación, democratizarse y contribuir al mejor funcionamiento del sistema monetario y financiero internacional, depende su continuidad como actor central de ese sistema. 